\title{
Active engine mounting control algorithm using neural network
}

\author{
Fadly Jashi Darsivan ${ }^{\mathrm{a}}$, Wahyudi Martono ${ }^{\mathrm{b}}$ and Waleed F. Faris ${ }^{\mathrm{a}, *}$ \\ ${ }^{a}$ Department of Mechanical Engineering, International Islamic University, Kuala Lumpur, Malaysia \\ ${ }^{\mathrm{b}}$ Department of Mechatronics, International Islamic University, Kuala Lumpur, Malaysia
}

Received 17 August 2007

Revised 15 June 2008

\begin{abstract}
This paper proposes the application of neural network as a controller to isolate engine vibration in an active engine mounting system. It has been shown that the NARMA-L2 neurocontroller has the ability to reject disturbances from a plant. The disturbance is assumed to be both impulse and sinusoidal disturbances that are induced by the engine. The performance of the neural network controller is compared with conventional PD and PID controllers tuned using Ziegler-Nichols. From the result simulated the neural network controller has shown better ability to isolate the engine vibration than the conventional controllers.
\end{abstract}

Keywords: Neural network, NARMA-L2, vibration isolation, conventional controller

\section{Introduction}

The mounting of an engine has basically three purposes, which are 1) to statically support the weight of the engine, 2) to prevent the engine from bouncing off the chassis during road disturbances and 3) to isolate the engine vibration to the chassis [1-5]. In order to achieve purpose 2) and 3) the engine mounting has to show two contradictory characteristics. To prevent the engine from bouncing off the chassis at low frequency level i.e. below $20 \mathrm{~Hz}$ the engine mount has to be as stiff as possible and posses a large amount of damping. This movement has to be constrained due to the tight compartment of today's automobile. However, at higher frequency level i.e. between $20-40 \mathrm{~Hz}$ the engine mount should exhibit the ability to isolate the engine vibration to the chassis by possessing low stiffness which may produce uncomfortable shake and noise in the vehicle's cabin [1,3,5-10].

Due to these contradictory characteristics has led manufacturers to design engine mounting with a certain trade off between engine vibration isolation and transient response. Furthermore, passive engine mount is efficient only at the high frequency range which therefore shows the inability for the mount to isolate engine disturbance at the lower frequency region such as during idling or when the air conditioner is switched on. Since also the demand for lighter vehicle and powerful engine has resulted in the adverse effect to the comfort of the passenger therefore, the evolution of an active engine mounting is necessary to overcome the limitations of the passive system [3,10-13].

The vibration induced by the engine is mainly caused by the motion of the reciprocating bodies such as the piston and connecting rod and also due the firing pulse of the internal combustion. Because of these vibrations the engine will be excited in all six degrees of freedom i.e. translational in the vertical (bounce), lateral and longitudinal directions and rotational about the vertical (yaw), lateral (roll) and longitudinal (pitch) axis $[1,8,11,14]$. However it was noted that the dominant excitation occurs along the vertical direction and is sinusoidal in nature $[10,12,15,16]$. Thus in this paper only the bounce disturbance is considered and the passive mount is modeled as a linear energy dissipating element with stiffness and damping along the vertical direction.

\footnotetext{
*Corresponding author. E-mail: waleed@iiu.edu.my.
} 
A lot have been reported on the control strategies of active engine mounting system which falls basically under the category of active vibration isolation. In active engine mounting the primary objective of the controller is disturbance rejection and the secondary is tracking capability [18]. In this report we are only going to focus on the former objective. As have been well established control strategies can fall under feedforward and feedback control. Example of a MIMO feedback vibration isolation of active engine mounting system can be found in [2] where the author has used the $\mathrm{H}_{2}$ controller design based on liberalized plant model. In [8] it was found that Jianming et al. have applied the hybrid approach in developing a two degree of freedom controller by combining both feedback and feedforward (filtered-x LMS algorithm) controller and in [9] the author has implemented a feedforward filtered-x LMS algorithm for vibration attenuation together with a hydraulic passive engine mounting. In [4] the performance of two adaptive-based algorithms namely filtered-x LMS and the proposed error-driven minimal controller synthesis (Er-MCSI) are compared in vibration isolation of an engine mount using an internal electromagnetic actuator as the active force component and in [11] Karimi and Lohmann has developed a relatively new robust optimal control for active vibration isolation of engine vibration based on Haar wavelet. Other examples of feedback and feedforward active engine mounting controllers can be found in $[5,10,12,16,17]$. In this paper we are proposing the application of neural network in direct inverse control architecture for attenuating the engine vibration to the chassis. It wad reported in [19-22] that neural networks such as the nonlinear autoregressive moving average (NARMA) has the ability to be trained and be used as a controller of a dynamic system and disturbance rejection. The applications of the neural network controllers have been realized by some researchers in the field of vibration control such as in [23] where the author implemented the neural network control for vibration isolation of a micro-manufacturing platform. In the paper the absolute acceleration of the micro-machining platform is fed back to the neural network controller as the input and uses a magnetostrictive actuator as the secondary force to attenuate the vibration. In [24,25] and [26] it was reported that neural network based controllers have been used in the application of active suspension systems. In [26] of the proposed neural network are compared with a conventional PID controller and have shown superior performance. The fundamentals theories of neural networks can be found in reference [29]. There had been a lot of research on the application of neural network in active or semiactive vibration control in general. The applications of neural network towards vibration control in automotive are mainly considered in the area of active suspension system such as in [25-27]. However, very little research focuses on the application of neural network such as NARMA-L2 neural controller in active engine mounting system. It was reported by [30] that another neural network controller which is the Extended Minimal Resource Allocating Network (EMRAN) has shown a promising performance in attenuating the vibration induce by the engine to the chassis. The objective of the paper is to compare the effectiveness of the direct inverse NARMA-L2 neruocontroller to Ziegler-Nichols tuned PD and PID controllers in the problem of active engine mounting system which so far has not been published. Unlike the conventional controllers where the mathematical model has to be defined prior to the controller design neural network does not require any of this model in its application. This is the main advantage of the neural network controller where design can be free of any tedious mathematical derivations.

The rest of the paper is presented based on the following arrangement. Sections 2 and 3 discuss some literature survey on existing passive, semi active and actuve engine mounts. Section 4 of the paper presents the mathematical foundation of the engine mounting system. In Section 5 the theoretical background of the Ziegler-Nichols conventional Proportional Derivative (PD) and Proportional Integral Derivative controllers based on the quarter decay ratio is presented and followed by Section 6 that shows the theory behind the NARMA-L 2 neural network controller. Section 7 illustrates the simulation and results of the active controlled engine vibration system for both the conventional controllers and the proposed neural networks controller. The comparison of conventional controller and artificial neural network (ANN) controller is also presented in this section and the results shows the superiority of the NARMA-L2 controller in terms of disturbance rejection. In Section 8 some conclusions are explained.

\section{Passive engine mount}

In the automotive industries there are two types of passive mounts that are commonly used. They are the rubber mount and hydraulic mount. This section describes the mechanics of these two types of passive mounts. 
Structure Side

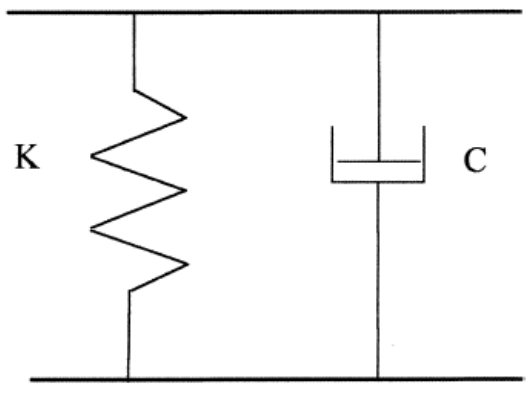

Engine Side

Fig. 1. Mechanical model of the elastomeric mount [31].

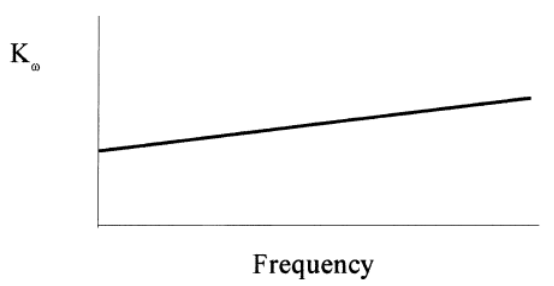

Fig. 2. Dynamic stiffness of rubber engine mount [31].

\subsection{Passive rubber mount}

Rubber mount has been successfully used to support the engine for decades. Its simple design and less effort to maintain make it popular among car manufacturers. Rubber mount normally consist of rubber bonded to a metal base which can either be conical in shape or circular. Figure 1 shows the mechanical model of the elastomeric mount.

The rubber or elastomeric mount can be mathematically represented by a stiffness, $\mathrm{k}$ and damping, c connected in parallel. The dynamic stiffness of the mount can be represented in Fig. 2.

It was noted that from the dynamic stiffness characteristic the stiffness of the rubber mount increases as the frequency increases. Since the design of the mount requires the stiffness of the mount to be high at lower frequency and small at higher frequency this clearly show that the rubber mount has to have a trade-off between engine bounce prevention and engine vibration isolation. Normally elastomeric mount is designed to have the necessary stiffness to perform well for vibration isolation.

\subsection{Hydraulic mount}

Hydraulic mount which is also known as fluid mount gained its popularity based on two reasons i.e. the first reason vehicles are made lighter and smaller, with low idle speed and the second reason hydraulic mount has evolved into a tunable device. In addition to a simple elastomeric mount hydraulic mount consists of two fluid chambers separated by a spiral shaped inertia track. In principle there are three types of hydraulic mounts. Hydraulic mount with simple orifice, hydraulic mount with inertia track and hydraulic mount with inertia track and a decoupler. Which ever the design the main purpose of the hydraulic mount is to increase its damping capacity at the disturbance frequency and thus vibration isolation at that frequency can be improved. The typical schematic diagram of hydraulic mounts can be depicted in Fig. 3.

At lower frequency level a hydraulic mount with inertia track will have the dynamic stiffness magnitude equal as to a rubber mount since the fluid is free to flow from one chamber to the other through the inertia track. As it 


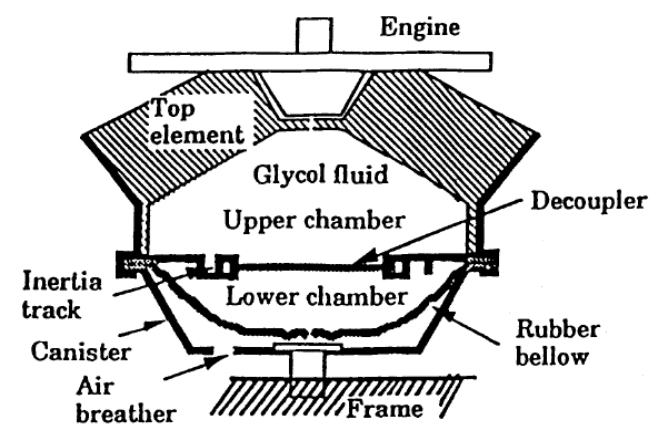

Fig. 3. Schematic diagram of a simple hydraulic mount with inertia track and decoupler [6].

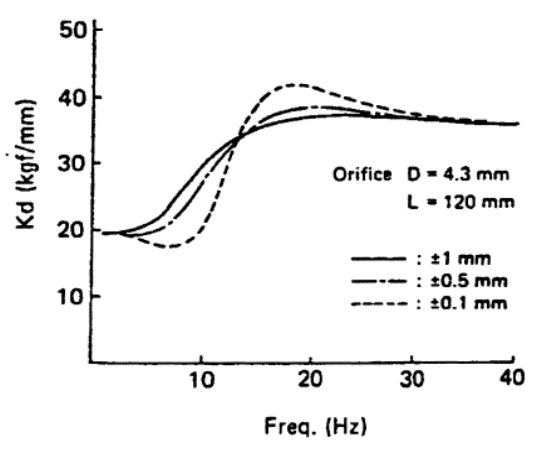

Fig. 4. Dynamic stiffness characteristic of hydraulic mount [32].

reaches the notch frequency $f_{n}$ the liquid that flows through the inertia track will resonates back and forth. This will eventually decreases the dynamic stiffness of the mount and improved the vibration isolation capability. As the frequency increases further until it reaches the resonance frequency, $f_{r}$, the dynamic stiffness of the mount will reach its maximum since the inertia track will eventually closes off and the total dynamic stiffness will be equal to the elastomeric stiffness $K_{r}$ and the volumetric stiffness $K_{t}$, Fig. 4 shows the dynamic stiffness characteristic of the hydraulic mount.

As for the hydraulic mount with inertia track and a decoupler at low amplitude the fluid will travel through the around the decoupler instead of the inertia track. This resulted the mount to behave as an elastomeric mount. As the amplitude increases the decoupler will be forced to bottom on its seat and thus terminating the fluid flow around it. Fluid will then be forced to enter the other chamber through the inertia track. At low frequency level the fluid moves freely through the track and as the frequency increases the fluid inside the track will resonates resulting in additional damping. When the natural frequency is reached the dynamic stiffness of the mount will be maximum and after the natural frequency the inertia track will closes off and the dynamic stiffness at this point will be the sum of the elastomeric stiffness and the volumetric stiffness. Figure 5 shows the dynamic stiffness of the hydraulic mount with inertia track and decoupler. As shown in the figure the dynamic stiffness of the mount is both frequency and amplitude dependent. At small amplitude i.e. $\pm 0.1 \mathrm{~mm}$ the mount will behave as an elastomeric mount and at higher amplitude i.e. $\pm 1.0 \mathrm{~mm}$ the mount will behave as a hydraulic mount with an inertia track.

\section{Semi active and active engine mounts}

Semi active engine mount sometime called adaptive engine mount can change the dynamic response of the system by changing its parameters such as stiffness and damping. Most common applications of semi active engine mount 

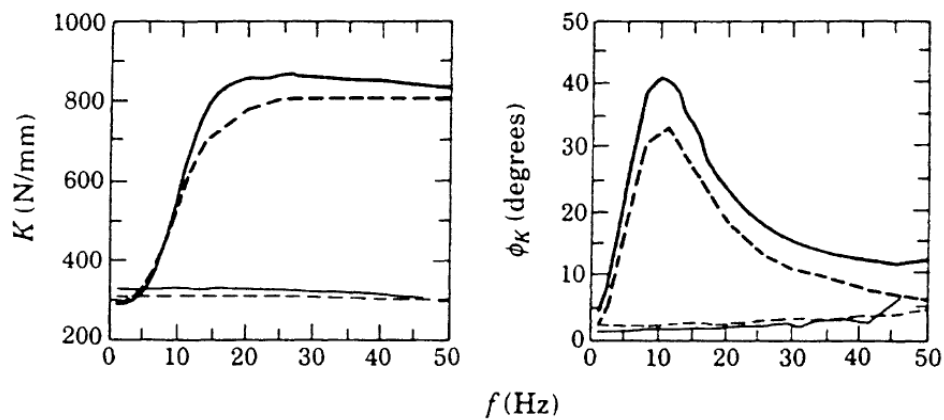

Fig. 5. Dynamic stiffness of hydraulic mount with decoupler [6].

Structure Side

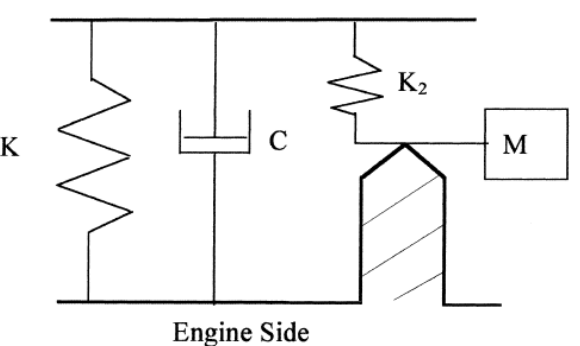

Fig. 6. Mechanical model of the adaptive hydraulic engine mount [31].

is either by using electrorheological fluids or magnethorheological fluids. In Electrorheological fluid is a type of smart fluid that has the capability to vary its damping coefficient by changing the viscosity of the fluid inside the mount once a high voltage is applied.

As for magnethorhelogical semi active mount a fluid filled mount with small sized iron particles plays a major role in varying the damping coefficient of the system. As current passed though a coil the iron particle will form a linear chain and changes the state of the system from fluidic to a quasi solid state thus increasing the damping capacity of the system. Figure 6 shows the mechanical model of the semi active hydraulic mount that is commonly used in the automotive industry.

However, it was noted by [1] that the semi active hydraulic engine mount was only effective to isolated vibration at the lower frequency range. Therefore, another type of engine mount was needed to improve the performance at the higher frequency range that is the active engine mount.

Active engine mount consists of a passive mount (rubber or hydraulic) and an external force actuator to counter the disturbance force. The purpose of the passive isolators is used as a fail safe mechanism in the event the external force actuator fails and the passive rubber also plays a major role to prevent the engine from bouncing off the vehicles chassis at low frequency and high amplitude disturbances. Figures 7 and 8 show the mechanical model of both the active rubber mount and the active hydraulic mount respectively.

From Fig. 7 it can be seen that the active rubber mount has an external force F, that will counteract with the disturbance force induced by the engine at the disturbance frequency. Normally the active force actuator will be placed in parallel with the passive rubber mount. The force actuator can either be electromagnetic actuator, electrohydraulic actuator, servohydraulic, electrostrictive and piezoelectric material or magnetostrictive material actuators [31]. Several important requirements that must be satisfied in choosing the actuator type are force, stroke, bandwidth, power limitations, size, weight, service life, temperature, and cost.

Active hydraulic mount can be tuned to have high stiffness at low frequency to prevent engine bounce and low stiffness at high frequency to increase isolation. The active hydraulic mount uses the controller to further drive the damping at the notch frequency to zero and thus producing prefect isolation. In the automotive application the 


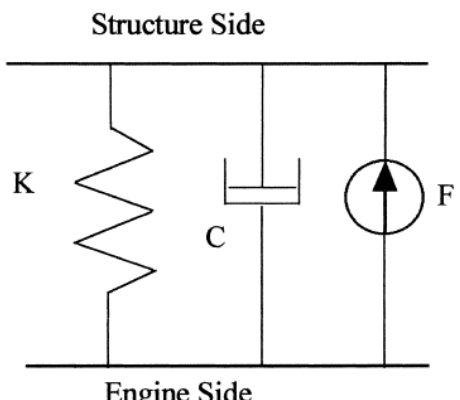

Fig. 7. Mechanical model of the active rubber mount [33].

K

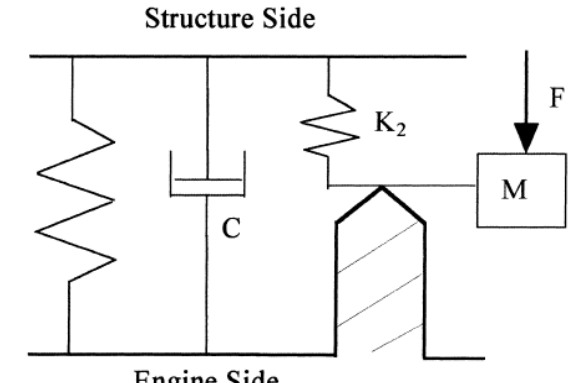

Fig. 8. Mechanical model of the active hydraulic mount [33].

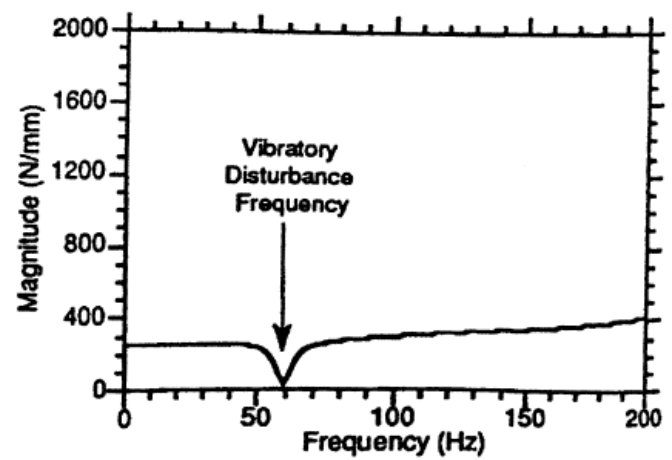

Fig. 9. Dynamic stiffness of the active rubber mount [31].

hydraulic mount will be tuned to achieve excellent damping at engine bounce frequency and at higher frequency the controller of the active hydraulic mount will then drive the dynamic stiffness to zero at higher frequency. Figures 9 and 10 illustrate the dynamic stiffness characteristic of both the active rubber mount and the active hydraulic mount respectively.

From the above discussion hydraulic passive mount could only isolate the vibration at certain frequency level and still show a large magnitude at frequency above its resonance frequency. From this discussion in this paper the active engine mounting system is introduced to overcome the above said problem. To demonstrate the superior capability of the active engine mount even at a disadvantageous condition a simple elastomeric mount is used instead of a more superior passive hydraulic mount. 


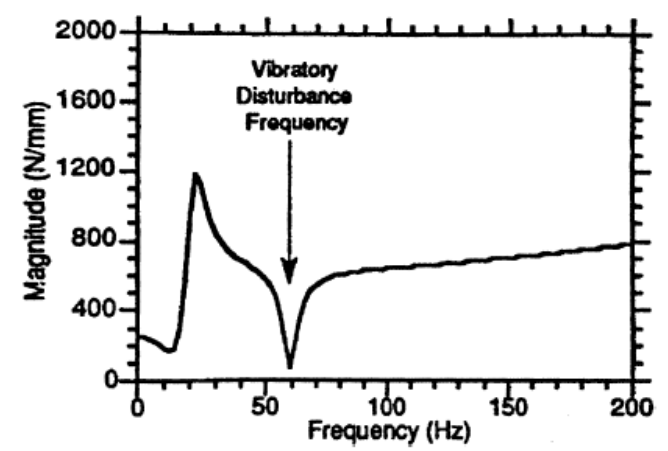

Fig. 10. Dynamic stiffness of the active hydraulic mount [31].

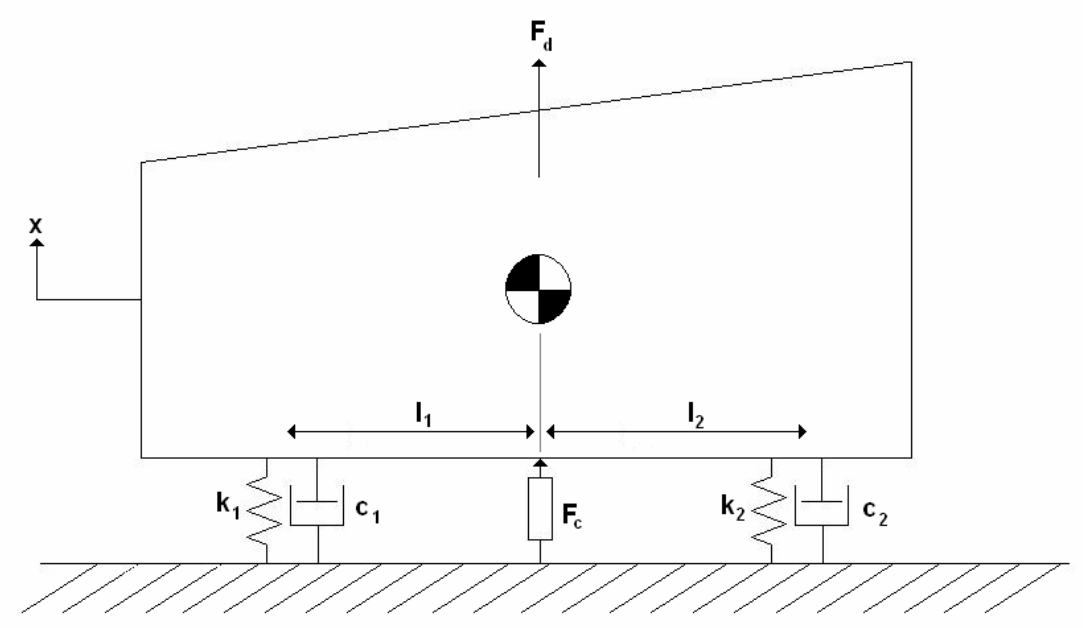

Fig. 11. A schematic diagram of an engine vibration system.

\section{Mathematical model of engine vibration system}

Figure 11 shows the schematic diagram of a two degree of freedom vibration system. The engine, which has a mass $\mathrm{m}$, has a centre of gravity of the engine located at $l_{1}$ and $l_{2}$ distances from the front mount and the rear mount respectively. The front engine mount has a stiffness and damping of $k_{1}$ and $c_{1}$ respectively and $k_{2}$ and $c_{2}$ are the stiffness and damping of the rear mount respectively and $F_{c}$ is the actuator force applied only to the engine. The rigid platform represents the chassis of the vehicle and since it is assumed that the displacement of the chassis is very small compared to the displacement of the engine, $x$, thus, the engine is said to be supported on a rigid platform. The engine is assumed to be subjected to bounce disturbance i.e. $F_{d}$. The bounce disturbance represents the secondary disturbance of the engine which is caused by the inertia of the piston, connecting rod and crank shaft. Applying Newton's equation of motion to the system gives the following relationships:

$$
\begin{aligned}
& M \ddot{x}=-k_{1} x_{1}-c_{1} \dot{x}_{1}-k_{2} x_{2}-c_{2} \dot{x}_{2}+F_{d}-F_{c} \\
& I \ddot{\theta}=-k_{1} x_{1} l_{1}-c_{1} \dot{x}_{1} l_{1}+k_{2} x_{2} l_{2}+c_{2} \dot{x}_{2} l_{2}
\end{aligned}
$$

where

$$
\begin{aligned}
& x_{1}=x-l_{1} \theta \\
& x_{2}=x+l_{2} \theta
\end{aligned}
$$


Selecting the state variable as:

$$
\begin{aligned}
& X_{1}=x \\
& X_{2}=\dot{x} \\
& X_{3}=\theta \\
& X_{4}=\dot{\theta}
\end{aligned}
$$

In state space Eqs (1) and (2) can be written as:-

$$
\dot{X}=A X+B U+D V
$$

where $U$ is the actuator force to the engine and $V$ is the bounce disturbance.

Rearranging Eqs (1) and (2) in the matrix form gives:

$$
\begin{aligned}
{\left[\begin{array}{l}
\dot{X}_{1} \\
\dot{X}_{2} \\
\dot{X}_{3} \\
\dot{X}_{4}
\end{array}\right]=} & {\left[\begin{array}{llll}
0 & 1 & 0 & 0 \\
-\frac{k_{1}+k_{2}}{M} & -\frac{c_{1}+c_{2}}{M} & \frac{k_{1} l_{1}-k_{2} l_{2}}{M} & \frac{c_{1} l_{1}-c_{2} l_{2}}{M} \\
0 & 0 & 0 & 1 \\
-\frac{k_{1} l_{1}-k_{2} l_{2}}{I}-\frac{c_{1} l_{1}-c_{2} l_{2}}{I} & \frac{k_{1} l_{1}^{2}+k_{2} l_{2}^{2}}{I} & \frac{c_{1} l_{1}^{2}+c_{2} l_{2}^{2}}{I}
\end{array}\right]\left[\begin{array}{l}
X_{1} \\
X_{2} \\
X_{3} \\
X_{4}
\end{array}\right] } \\
& +\left[\begin{array}{l}
0 \\
-\frac{1}{M} \\
0 \\
0
\end{array}\right] F_{c}+\left[\begin{array}{l}
0 \\
\frac{1}{M} \\
0 \\
0
\end{array}\right] F_{D}
\end{aligned}
$$

and the output matrix can be written as:

$$
\left[\begin{array}{l}
Y_{1} \\
Y_{2}
\end{array}\right]=\left[\begin{array}{llll}
1 & 0 & -l_{1} & 0 \\
1 & 0 & l_{2} & 0
\end{array}\right]\left[\begin{array}{l}
X_{1} \\
X_{2} \\
X_{3} \\
X_{4}
\end{array}\right]
$$

If we multiply Eq. (7) and its derivative with stiffness, $k$, and damping, $c$, of the passive mounts we can obtain the transmitted force to the chassis at point 1 and point 2 i.e. the front and the rear as shown below:

$$
\begin{aligned}
& F_{T 1}=k_{1} Y_{1}+c_{1} \dot{Y}_{1} \\
& F_{T 2}=k_{2} Y_{2}+c_{2} \dot{Y}_{2}
\end{aligned}
$$

From Eq. (6) it can be observed that the translational disturbance has effected both the angular displacement and linear displacement. For simplicity we assume that $k_{1}=k_{2}=k, c_{1}=c_{2}=c$ and $l_{1}=l_{2}=l$ then the system can be uncoupled and the matrix A from in Eq. (6) can be rewritten as:

$$
[A]=\left[\begin{array}{llll}
0 & 1 & 0 & 0 \\
-\frac{2 k}{M}-\frac{2 c}{M} & 0 & 0 \\
0 & 0 & 0 & 1 \\
0 & 0 & \frac{2 k l^{2}}{I} & \frac{2 c l^{2}}{I}
\end{array}\right]
$$

and thus the system reduces from a two degree of freedom system to two single degree of freedom systems in which the disturbance is totally independent of the angular displacement. For this particular example the natural frequency and damping ratio for both the bounce $\left(\omega_{x}\right.$ and $\left.\zeta_{x}\right)$ and pitch $\left(\omega_{\theta}\right.$ and $\left.\zeta_{\theta}\right)$ modes can be deduced to be the following relationships [34]:

$$
\begin{aligned}
& \omega_{x}=\sqrt{\frac{2 k}{M}} \quad, \quad \varsigma_{x}=\frac{c}{\sqrt{2 M k}} \\
& \omega_{\theta}=l \sqrt{\frac{2 k}{I}}, \quad \varsigma_{\theta}=\frac{c l}{\sqrt{2 I k}}
\end{aligned}
$$




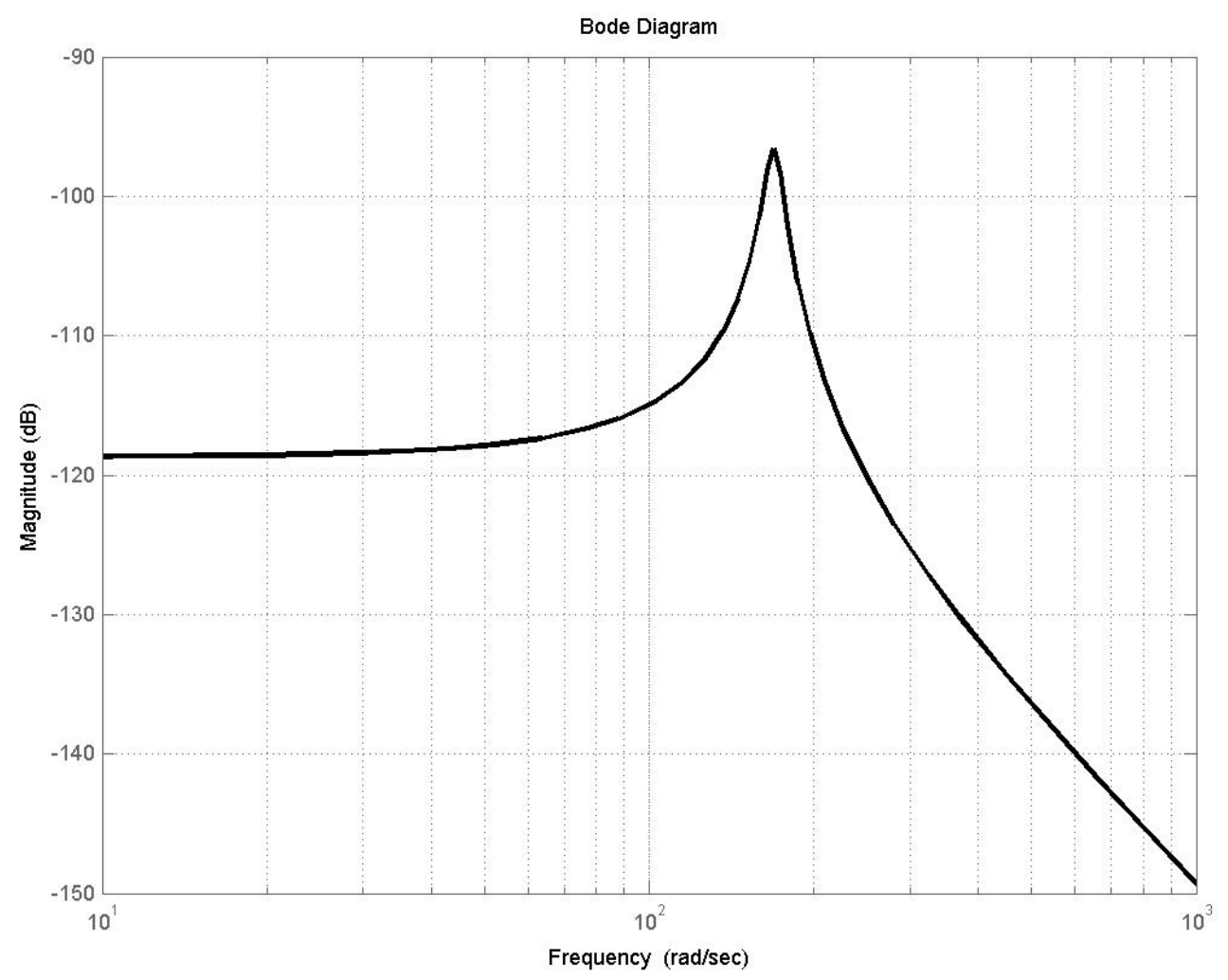

Fig. 12. Bode Plot of the force transmissibility.

Replacing Eq. (10) into Eq. (6) and partitioning the matrix into two gives the following independent relationships:

$$
\begin{aligned}
& {\left[\begin{array}{l}
\dot{X}_{1} \\
\dot{X}_{2}
\end{array}\right]=\left[\begin{array}{ll}
0 & 1 \\
-\frac{2 k}{M}-\frac{2 c}{M}
\end{array}\right]\left[\begin{array}{l}
X_{1} \\
X_{2}
\end{array}\right]+\left[\begin{array}{l}
0 \\
-\frac{1}{M}
\end{array}\right] F_{c}+\left[\begin{array}{l}
0 \\
\frac{1}{M}
\end{array}\right] F_{D}} \\
& {\left[\begin{array}{c}
\dot{X}_{3} \\
\dot{X}_{4}
\end{array}\right]=\left[\begin{array}{ll}
0 & 1 \\
\frac{2 k l}{I} & \frac{2 c l}{I}
\end{array}\right]\left[\begin{array}{l}
X_{3} \\
X_{4}
\end{array}\right]}
\end{aligned}
$$

Equating $F_{c}=0$ and relating the total transmitted force to the disturbance force we can obtain the force transmissibility transfer function:

$$
\frac{F_{T}(s)}{F_{D}(s)}=\frac{2 \varsigma_{x} s+\omega_{x}^{2}}{s^{2}+2 \varsigma_{x} \omega_{x} s+\omega_{x}^{2}}
$$

Simulating this relationship will give us the result (Fig. 12). From Fig. 12 shows the dynamic performance of a passive elastomeric mount. We can see that at lower frequency range i.e. below the resonance frequency the equivalent magnitude of the disturbance force will be transmitted to the chassis through the mount and at higher frequency range i.e. above the resonance frequency the passive mount is able to isolate some vibration induced by the engine disturbance. Obviously the isolation performance of the passive mount is limited to the frequency range above the resonance frequency. One may argue that this resonance frequency can be altered by changing the stiffness parameters of the mount as in Eq. (11). However, we should note that it is very unlikely that this would happen since in the automotive industry altering fixed parameters in assembled vehicles would cause a large amount of investment. Thus, we believe by introducing an active engine mount system to existing assembled vehicles could solve this problem less expensively. 


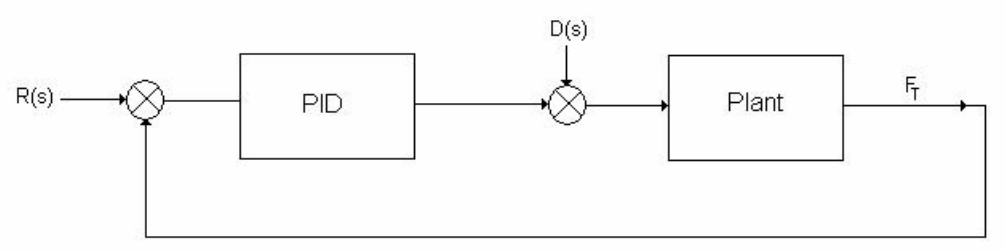

Fig. 13. Block diagram of the Ziegler-Nichols tuned PID controller.

\section{Ziegler-nichols tuned controller}

In this paper the performance of two types of controllers are compared based on their ability to isolate the force induced by the engine to the chassis. The first type of controller is a PID type controller tuned by using ZieglerNichols method. Ziegler and Nichols proposed two methods for tuning a PID controller and the method used in this research is based on the decay ratio of 0.25 [35]. Figure 13 shows the block diagram of the system.

The transmitted force is taken as the feedback parameter to the system and thus the control force $F_{c}$ is described by using the following relationship:

$$
F_{c}(t)=K_{p}\left(e(t)+T_{d} \frac{d e(t)}{d t}+\frac{1}{T_{i}} \int e(t) d t\right)
$$

where,

$$
e(t)=r-F_{T}
$$

Since the purpose of the controller is to isolate the induced vibration to the chassis thus, $r=0$. The error derivative in Eq. (17) represents the mass multiply by the jerk and the error integral term represents the impulse [36].

To tune the PID controller using Ziegler-Nichols quarter decay ratio the controller parameter is increased from 0 until the transient response of the system after 1 period shows a decay of $25 \%$ as shown in Fig. 14.

Then the value of $K_{p}, T_{i}$ and $T_{d}$ are calculated based on factors given in Table 1.

\section{The neural network controller}

In this paper Nonlinear Autoregressive Moving Average (NARMA-L2) neural network is used as plant identification and control. The first step when using neural network controller is plant identification process. The performance of the neural network controller relies heavily on how accurate the neural network can represent the plant or the system by adjusting its weights and biases based on the system input-output data. The accuracy of the model output compared to the actual plant output is found through the calculation of the neural network mean square error (MSE) given as:

$$
E=\frac{1}{N} \sum_{i=1}^{N}\left(y_{p i}-y_{m i}\right)^{2}
$$

Where $y_{p}$ is the target plant output and $y_{m}$ is the neural network output. Figure 15 shows how the neural network can be trained offline so that after an adequate training iteration, $E \approx 0$ or small enough that will make $y_{m} \approx y_{p}$.

For NARMA-L2 neural network controller the plant identification can be defined mathematically as the following equation [20]:

$$
\begin{aligned}
\hat{y}(k+d)= & f[y(k), y(k-1), \ldots, y(k-n+1), u(k-1), \ldots, u(k-m+1)] \\
& +g[y(k), y(k-1), \ldots, y(k-n+1), u(k-1), \ldots, u(k-m+1)] \cdot u(k)
\end{aligned}
$$

where, $u(k)$ is the system input and $y(k)$ is the system output and " $d$ " shows the delay of the parameters. From Eq. (19) we can see that NARMA-L2 neural network controller uses two neural networks for identification and 
Table 1

Ziegler-Nichols Tuning for the Regulator $D(s)=K_{p}\left(1+1 / T_{i} s+T_{d} s\right)$, for a decay ratio of 0.25

\begin{tabular}{ll}
\hline Type of controller & Optimum gain \\
\hline PID & $K_{p}=1.2 / \mathrm{RL}$ \\
& $T_{i}=2 \mathrm{~L}$ \\
& $T_{d}=0.5 \mathrm{~L}$ \\
\hline
\end{tabular}

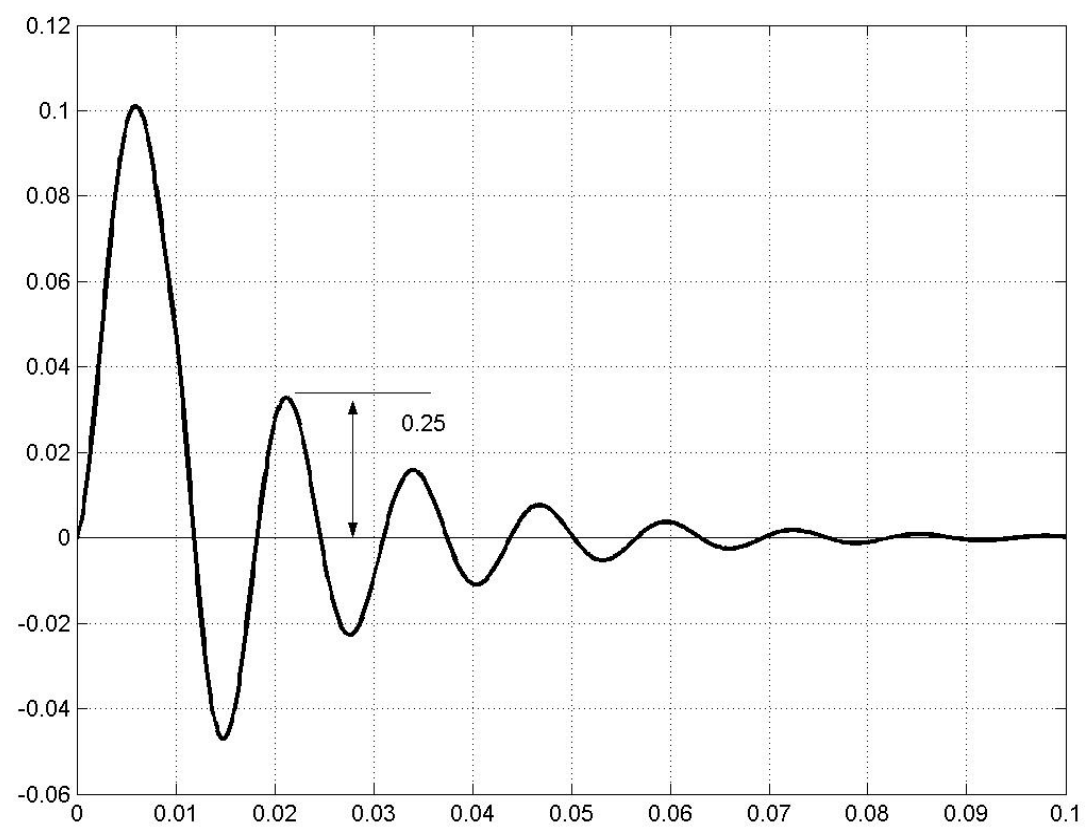

Fig. 14. The response of the system based on the quarter decay ratio.

control i.e. $f()$ and $g()$. The size of the input layer and the hidden layer is chosen based on trial and error basis since there is no hard fact rules that mentioned anything with regards to the structure of the network for any specific applications.

The second step for neural network application is to identify the inverse of the plant that we want to control. By having the inverse of the plant the control input can be identified based on the desired output. Therefore, rearranging Eq. (19) the control input to the plant can be determined by the following equation:

$$
u(k)=\frac{y_{r}(k+d)-f[y(k), y(k-1), \ldots, y(k-n+1), u(k-1), \ldots, u(k-n+1)]}{g[y(k), y(k-1), \ldots, y(k-n+1), u(k-1), \ldots, u(k-n+1)]}
$$

where $y_{r}(k+d)$ is the desired plant output.

\section{Simulations and results}

For the purpose of simulation the parameters in Table 2 are used.

The active engine vibration isolation system is simulated using Matlab software. The Ziegler-Nichols PID tuned controller is simulated by using the decay ratio of 0.25 . By using impulse disturbance as the input to the plant the 
Table 2

The parameter of the simulation of engine vibration [8]

\begin{tabular}{ll}
\hline Parameter & Value \\
\hline Mass, m & $30 \mathrm{~kg}$ \\
Stiffness, k & $4.3 \mathrm{e} 5 \mathrm{~N} / \mathrm{m}$ \\
Damping, c & $200 \mathrm{~N} / \mathrm{ms}$ \\
Length, 1 & $0.18 \mathrm{~m}$ \\
\hline
\end{tabular}

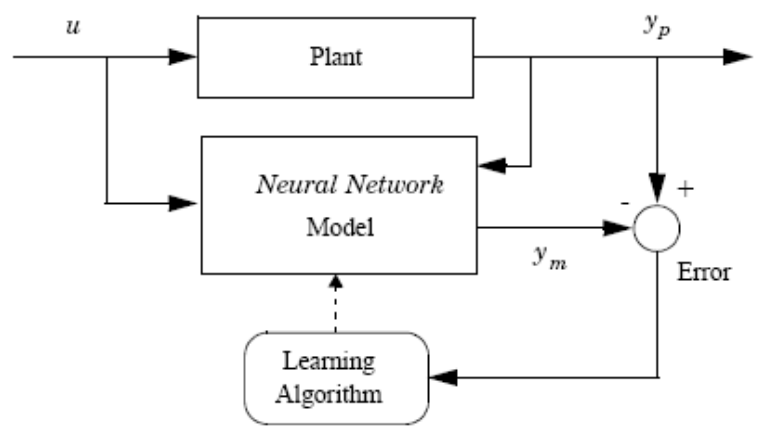

Fig. 15. Plant identification of the neural network [37].

proportional gain of the controller is increased until the decay of the first period is approximately 0.25 of the steady state value.

First, a proportional derivative (PD) type controller is simulated when the engine is subjected to impulse and a sinusoidal disturbance, where $K_{p}=18.0012$ and $K_{d}=2.3239$. The impulse disturbance may represent a sudden misfiring or a sudden speed fluctuation during idling. The amplitude and the duration of the impulse disturbance are $1 \mathrm{~N}$ and $0.01 \mathrm{~s}$ respectively. The sine wave disturbance is assumed to have amplitude of $1 \mathrm{~N}$ and a frequency of 18 $\mathrm{Hz}$ which is approximately the idle frequency of the vehicle. To test the effectiveness of the controller a disturbance of $1 \mathrm{~Hz}$ is used.

The simulated results for the impulse disturbance and the sinusoidal disturbance with a frequency of $1 \mathrm{~Hz}$ are shown in Figs 16 and 17 respectively. In Fig. 16 the dashed line shows the open loop response of the system when subjected to the impulse disturbance. The force transmitted to the chassis will have maximum amplitude of approximately $0.7 \mathrm{~N}$ and will gradually reduce due to the damping of the passive mount. At approximately 0.7 seconds the transmitted force achieves steady state the passenger's comfort will increase. When proportionaldifferential controller is used (solid line) it can be observed the maximum transmitted force is approximately $0.2 \mathrm{~N}$ and the force decreases gradually and reach steady state. However, it can be observed that there is a steady error in the PD controlled system when compared with the open loop system. From Fig. 16 it can be observed that the system has an overshoot of approximately $22 \%$, a settling time of approximately $0.25 \mathrm{~s}$ and a steady state magnitude of $0.0143 \mathrm{~N}$ which gives a steady state error of $1.143 \%$.

In Fig. 17 the maximum transmitted force for an open loop system is approximately $0.5 \mathrm{~N}$ when subjected to a sinusoidal disturbance at a frequency of $1 \mathrm{~Hz}$. It is noted that when the PD controller is applied to the system the transmitted force is suppressed to approximately $0.2 \mathrm{~N}$ which is $60 \%$ lower than the open loop system. This shows that the PD controller has managed to isolate the disturbance at a frequency of $1 \mathrm{~Hz}$.

Figure 18 shows the simulated result of the PD controller when the system is subjected to a disturbance at the idling frequency i.e. approximately $1000 \mathrm{rpm}$ for 10 seconds. To illustrate a more accurate view Fig. 19 shows the response of the system at the final 1 seconds of the simulation. As the disturbance frequency is increased to the idling frequency it can be observed that the transmitted force to chassis increases up to approximately $0.8 \mathrm{~N}$. At this frequency the vibration to the chaises would be very noticeable that it creates shaking to the chassis and discomfort to the passenger. With detail view of Fig. 19 the PD controlled system has managed to suppress the transmitted force 


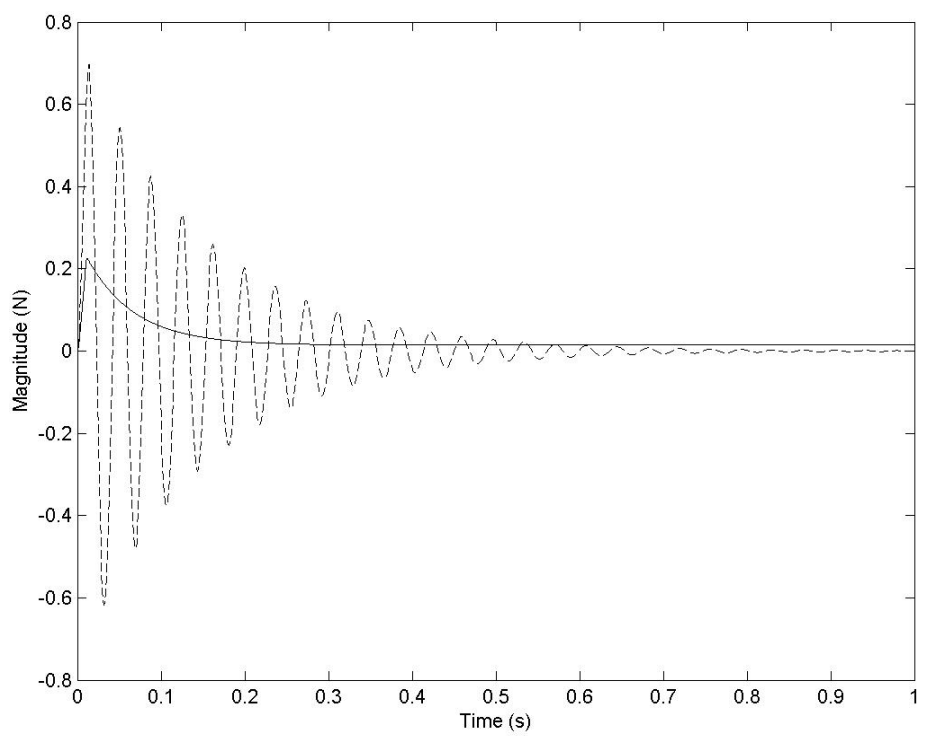

Fig. 16. Transmitted force variations of the system using the PD controller subjected to impulse engine disturbance. Open loop (-) and PD controlled (solid).

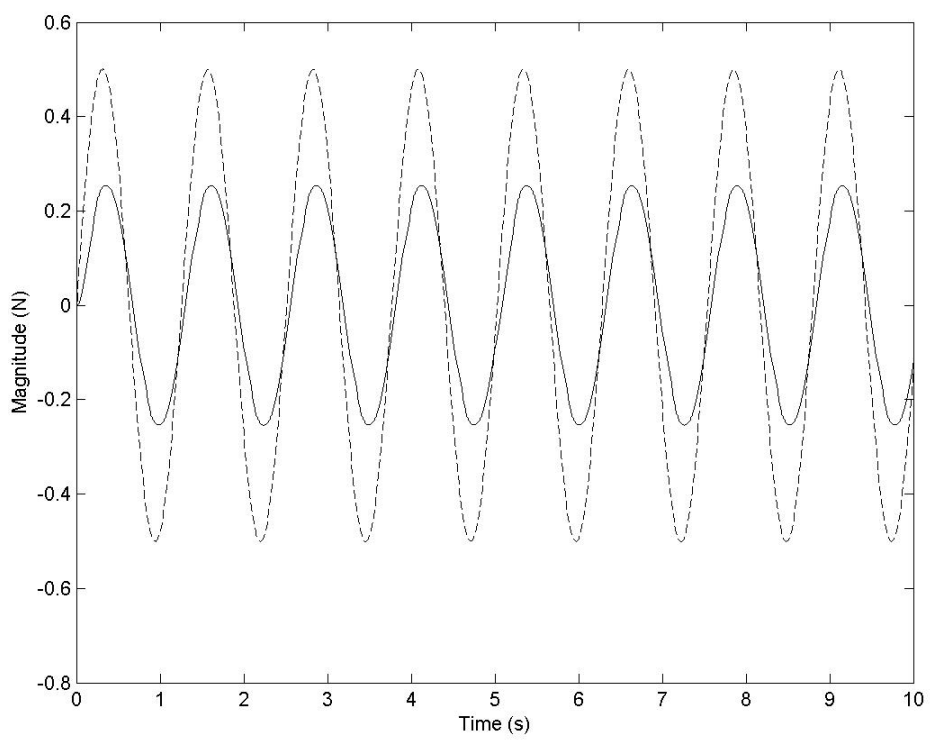

Fig. 17. Transmitted force variations of the system using the PD controller subjected to periodic engine disturbance at $1 \mathrm{~Hz}$. Open loop (-) and PD controlled (solid).

from $0.8 \mathrm{~N}$ to approximately $0.2 \mathrm{~N}$. Which is approximately $75 \%$ transmitted force reduction. Even though, there is a phase error between the open loop and PD controlled system the vibration induced by the engine is successfully suppressed by using this controller.

Figures 20 through 23 show the response of the system when using a PID controller. Here the gain of $K_{p}, K_{i}$ and $K_{d}$ are equivalent to $18.0012,34.8605$ and 2.3239 respectively. As before the impulse response of the open loop 


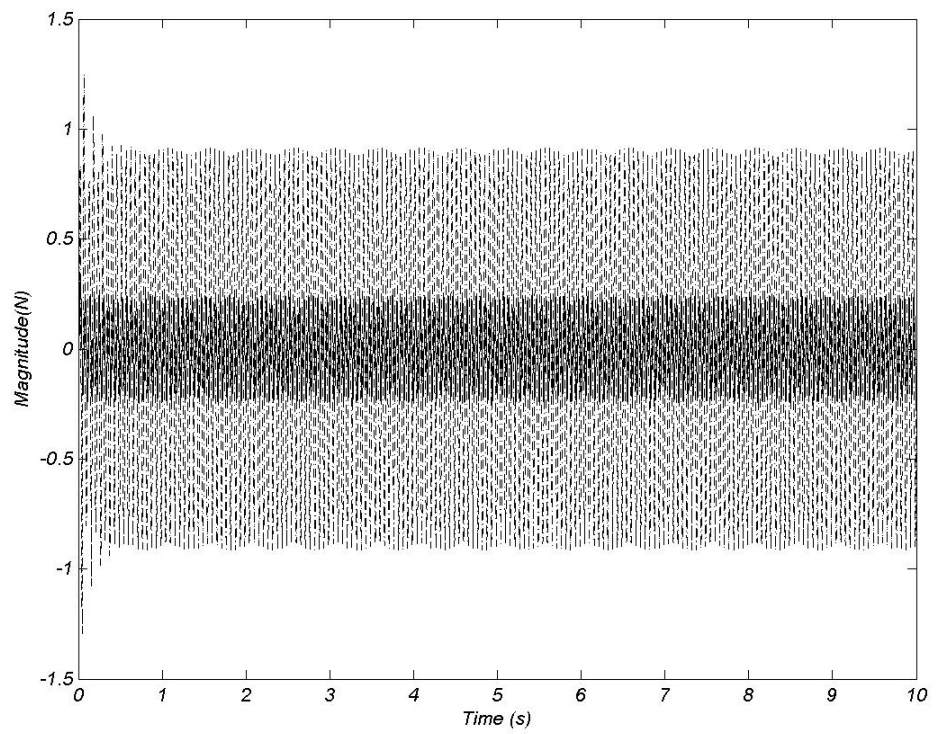

Fig. 18. Transmitted force variations of the system using the PD controller subjected to periodic engine disturbance at idling frequency. Open loop (-) and PD controlled (solid).

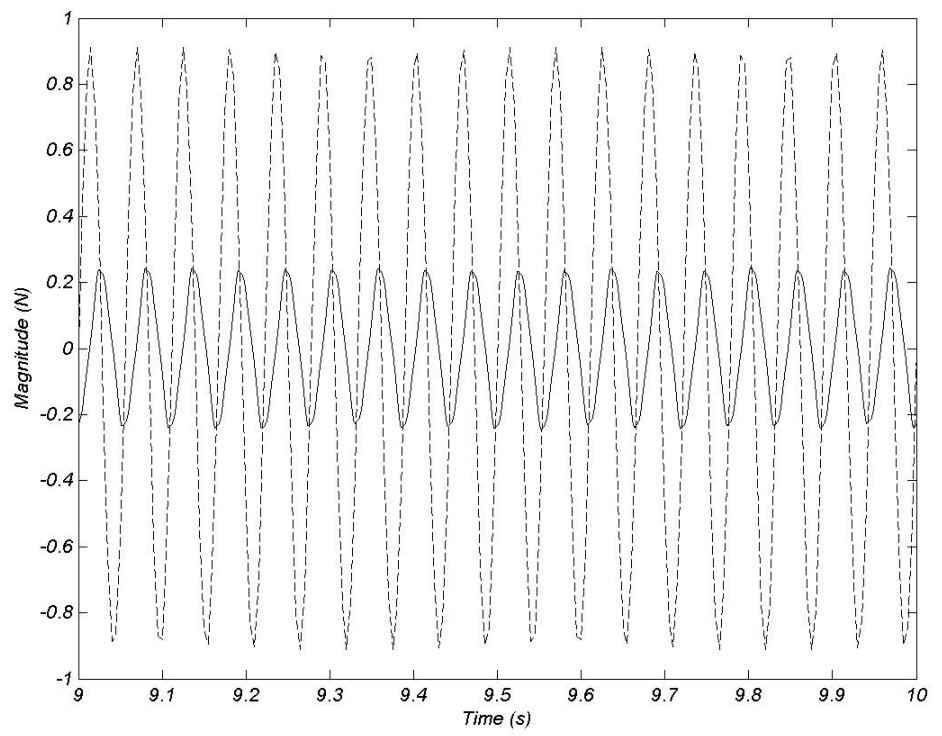

Fig. 19. Transmitted force variations of the system using the PD controller subjected to periodic engine disturbance at idling frequency at the final 1 seconds of the simulation. Open loop (-) and PD controlled (solid).

system would give a maximum transmitted force of approximately $0.7 \mathrm{~N}$ and will gradually decrease its magnitude due to the damping of the passive mount. With the PID controller implemented to the system it shows that the response of the transmitted force will reach a maximum magnitude of approximately $0.2 \mathrm{~N}$ and will eventually reach a steady state response close to $0 \mathrm{~N}$ i.e. $0.5 \times 10^{-3} \mathrm{~N}$. This shows an improvement compared to the PD controlled system. It can be seen from the figure that the system has an overshoot of $22 \%$ and a settling time of $0.25 \mathrm{~s}$. 


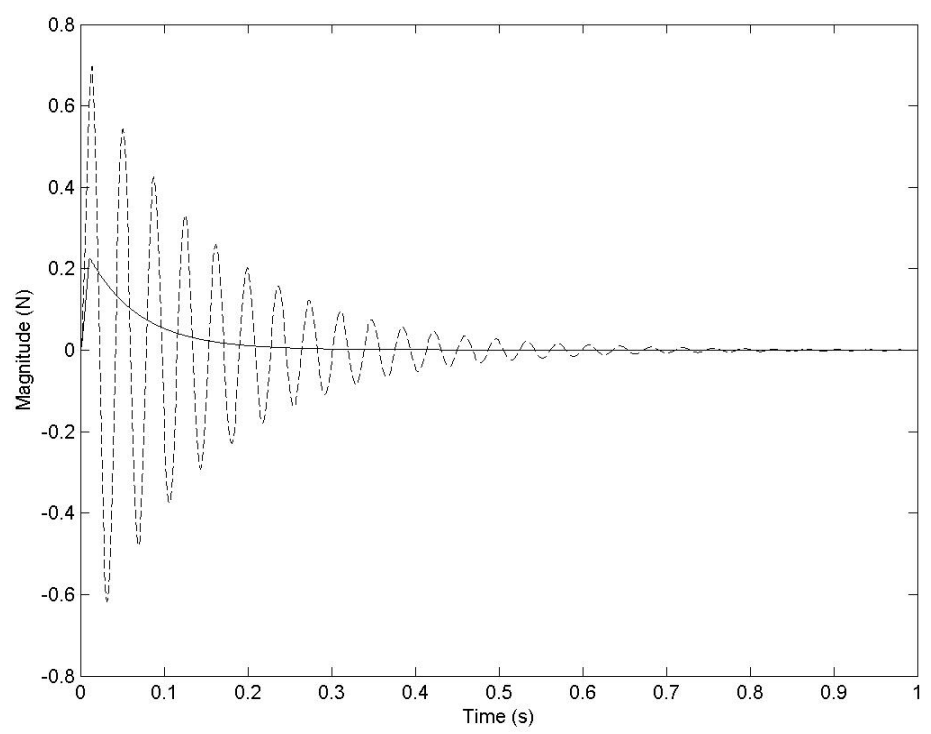

Fig. 20. Transmitted force variations of the system using the PID controller subjected to impulse engine disturbance. Open loop (-) and PID controlled (solid).

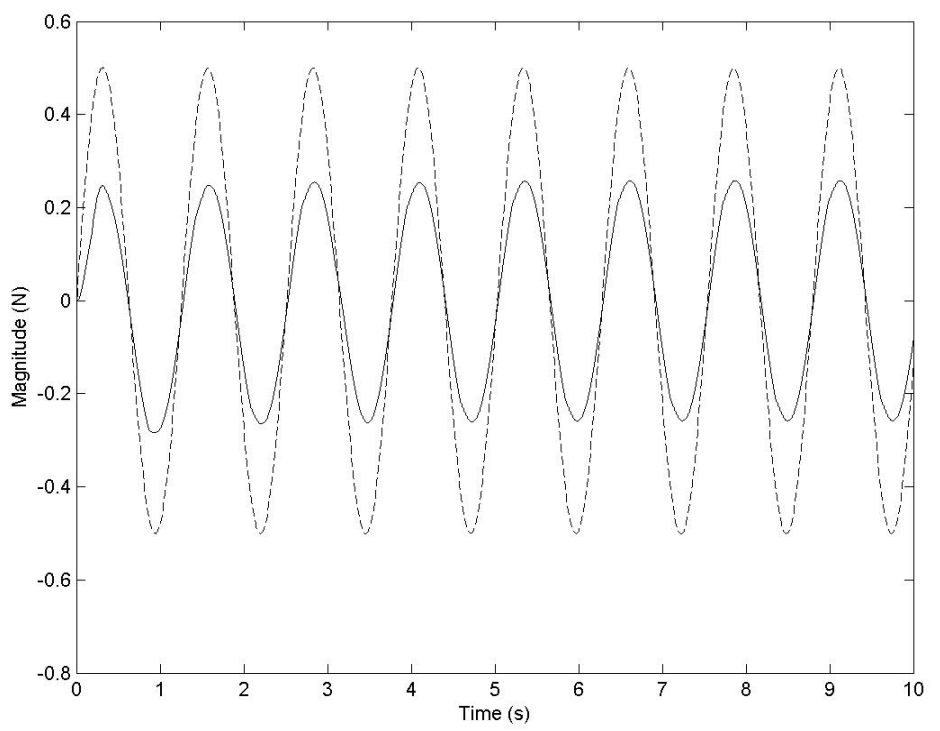

Fig. 21. Transmitted force variations of the system using the PID controller subjected to periodic engine disturbance at $1 \mathrm{~Hz}$. Open loop (-) and PD controlled (solid).

Figure 21 shows how the PID controlled system suppressed the vibration induced by a disturbance at $1 \mathrm{~Hz}$. As with the PD controlled system the PID controller has managed to suppress the transmitted force from $0.5 \mathrm{~N}$ to approximately $0.2 \mathrm{~N}$ which is again $60 \%$ reduction.

From a more detailed view in Fig. 23 the open loop system is again subjected to the sinusoidal disturbance at idle frequency and transmits a force of approximately $0.8 \mathrm{~N}$. It is observed that there is no further improvement with 


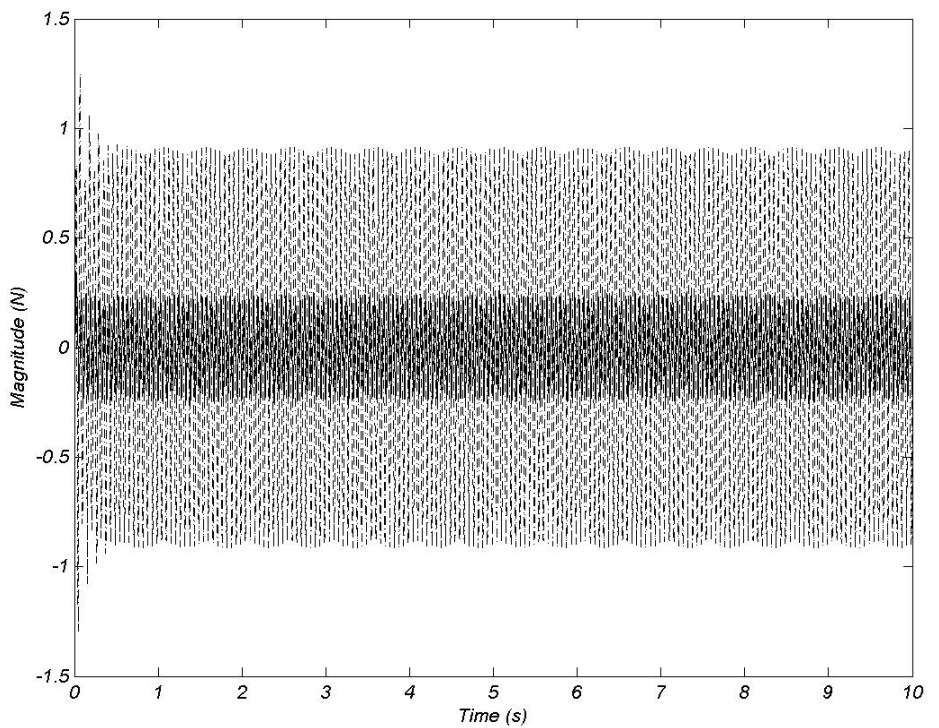

Fig. 22. Transmitted force variations of the system using the PID controller subjected to periodic engine disturbance at idling frequency. Open loop (-) and PD controlled (solid).

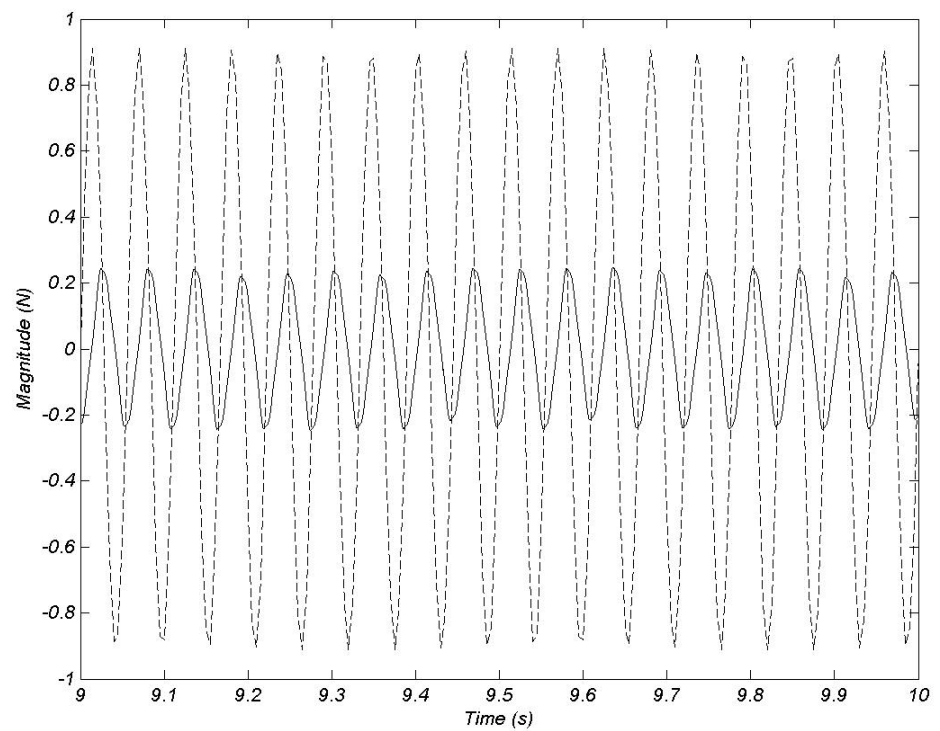

Fig. 23. Transmitted force variationsof the system using the PID controller subjected to periodic engine disturbance at idling frequency at the final 1 seconds of the simulation. Open loop (-) and PID controlled (solid).

respect to the vibration suppression at this frequency since the PID controller also isolates the vibration up to $0.2 \mathrm{~N}$ which is similar to the performance of the PD controlled system. However, the objectives of both of the controllers have been achieved that is to actively isolate the vibration induced by the engine to the chassis.

As for the neural network controller, it is initially trained offline by using Levenberg-Marquardt backpropagation algorithm. The neural network consists of 3 input layers, 1 hidden layer with 5 neurons and 1 output layer with 


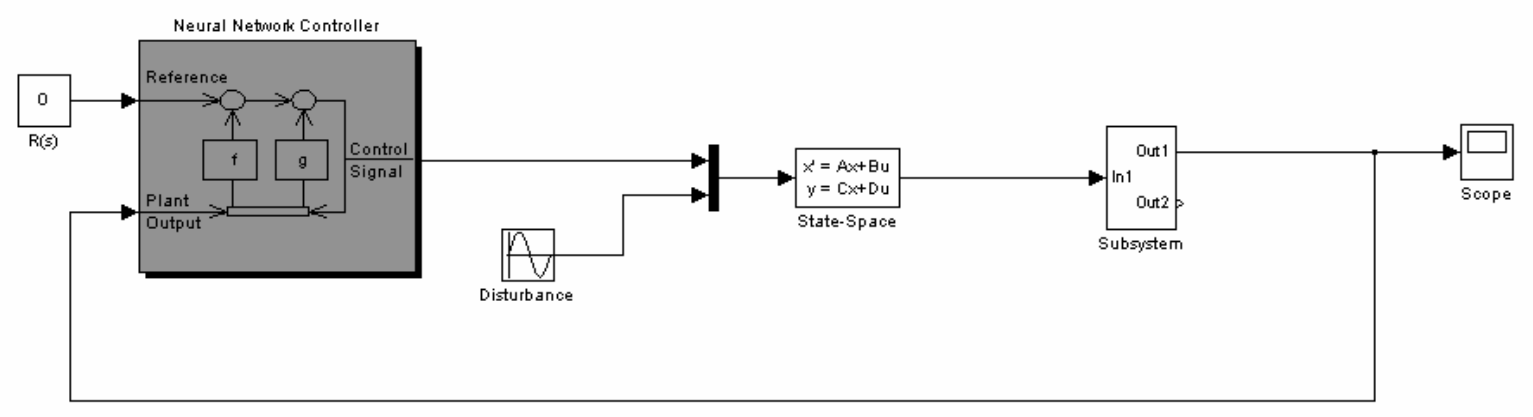

Fig. 24. Matlab realization of the system.

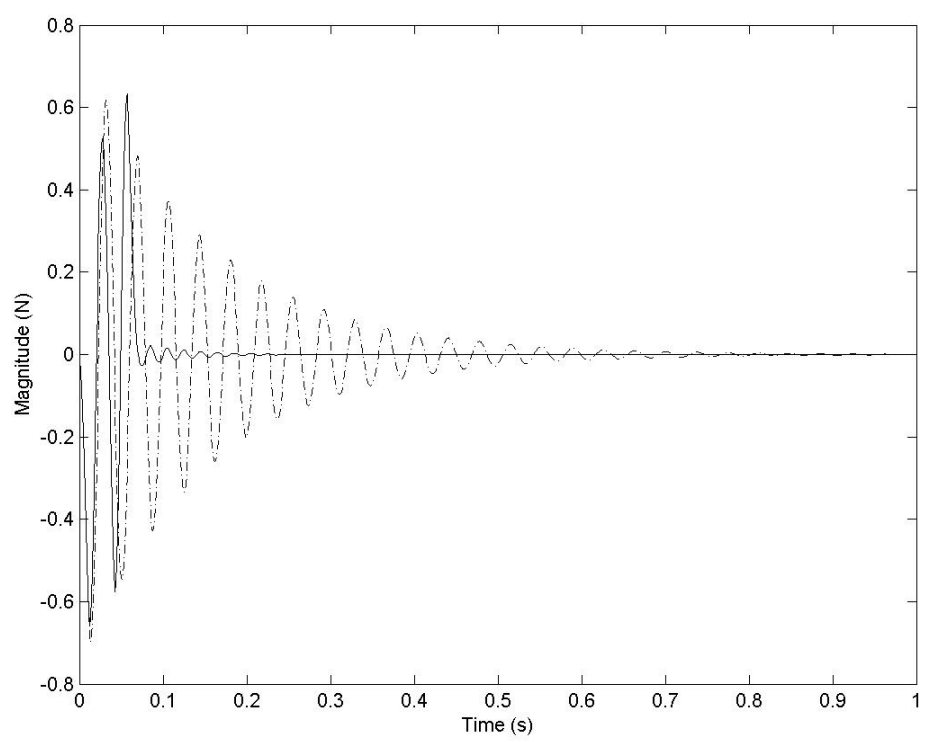

Fig. 25. Transmitted force variations of the system using the NN controller subjected to impulse engine disturbance. Open loop (-.-) and NN controlled (solid).

sigmoidal functions in the hidden layer and a linear function at the output layer. Once the training is complete the neural network is implemented to the system as shown in Fig. 24.

Figures 25, 26 and 27 show the simulated resulted of the system subjected to impulse and sinusoidal disturbances at a frequency of $1 \mathrm{~Hz}$ respectively. From Fig. 25 the NARMA-L2 controlled system has shown a very high overshoot if compared to the PD or PID controlled system. However, the overshoot suddenly minimized and the system achieves the steady state response much faster i.e. within a fraction of a second. It can be seen from the figure that the overshoot of the system is approximately $60 \%$, the settling time is $0.2 \mathrm{~s}$ and the steady state response of the system is $2.0141 \times 10^{-6} \mathrm{~N}$. When the system is subjected to a sinusoidal disturbance at $1 \mathrm{~Hz}$ the NARMA-L2 controller manage to isolate the transmitted force up to approximately $0.15 \mathrm{~N}$ which is $70 \%$ reduction. This shows a further improvement if compared to the PD and PID controller. However, there is a phase error occurring at this frequency. Table 3 summarizes the performance of the three types of controllers when subjected to impulse disturbance.

Figure 27 illustrates the disturbance rejection at idling frequency when using the NARMA-L2 neural network controller and Fig. 28 illustrates the simulated result at the final 10 seconds of the simulation. From Fig. 23 a total of approximately $65 \%$ transmitted force has been successfully isolated allowing only $0.15 \mathrm{~N}$ forces to be transmitted to 


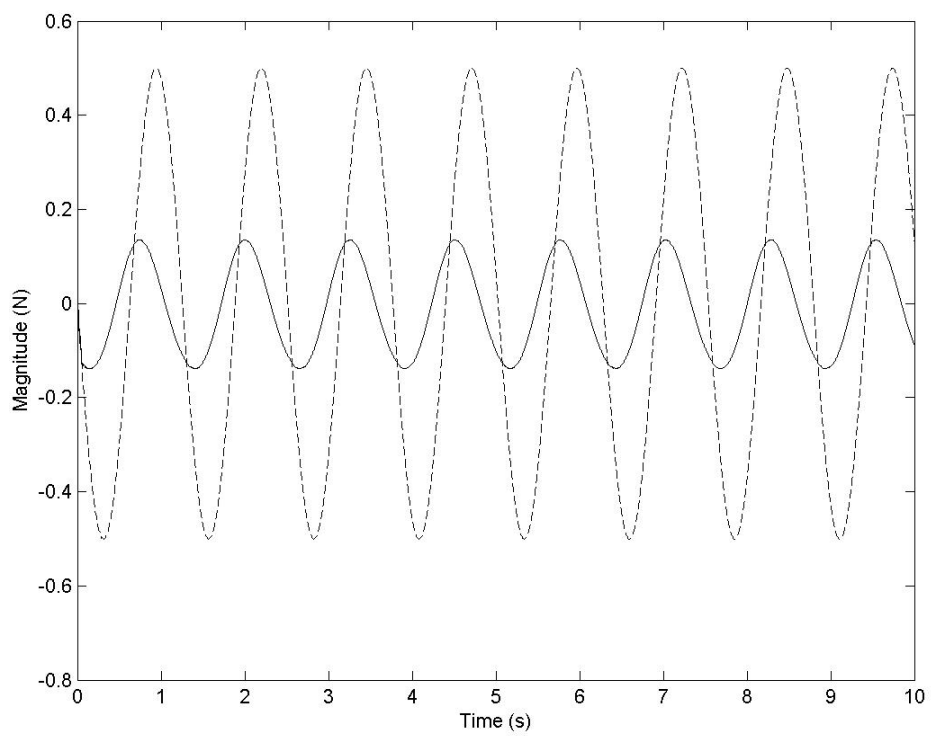

Fig. 26. Transmitted force variations of the system using the NN controller subjected to periodic engine disturbance. Open loop (-) and NN controlled (solid).

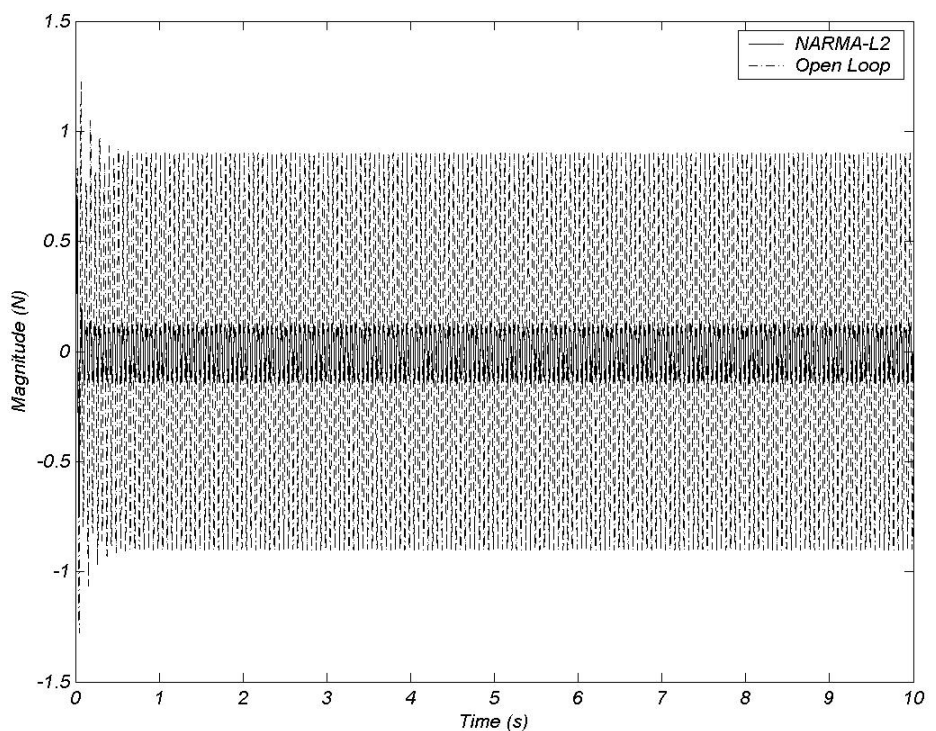

Fig. 27. Transmitted force variations of the system using the NN controller subjected to periodic engine disturbance at $18 \mathrm{~Hz}$. Open loop (-) and NN controlled (solid).

the chassis. However, unlike the conventional controllers at the idling frequency the NARMA-L2 controller shows no phase error.

From Table 3 it can be noted that neural network controller is able to isolate the transmitted force induced by the engine very effectively with faster settling time even though the over shoot is a little too high compared to the other two controllers. 
Table 3

Performance comparison of the three types of controllers

\begin{tabular}{lccc}
\hline Controller & \% Overshoot & $\begin{array}{c}\text { Settling } \\
\text { time }(\mathrm{s})\end{array}$ & $\begin{array}{c}\text { Steady state } \\
\text { response }(\mathrm{N})\end{array}$ \\
\hline [-8pt] PD & 24 & 0.25 & 0.0413 \\
PID & 24 & 0.25 & $0.5 \mathrm{e}-3$ \\
Neural network & 60 & 0.2 & $2.0141 \mathrm{e}-6$ \\
\hline
\end{tabular}

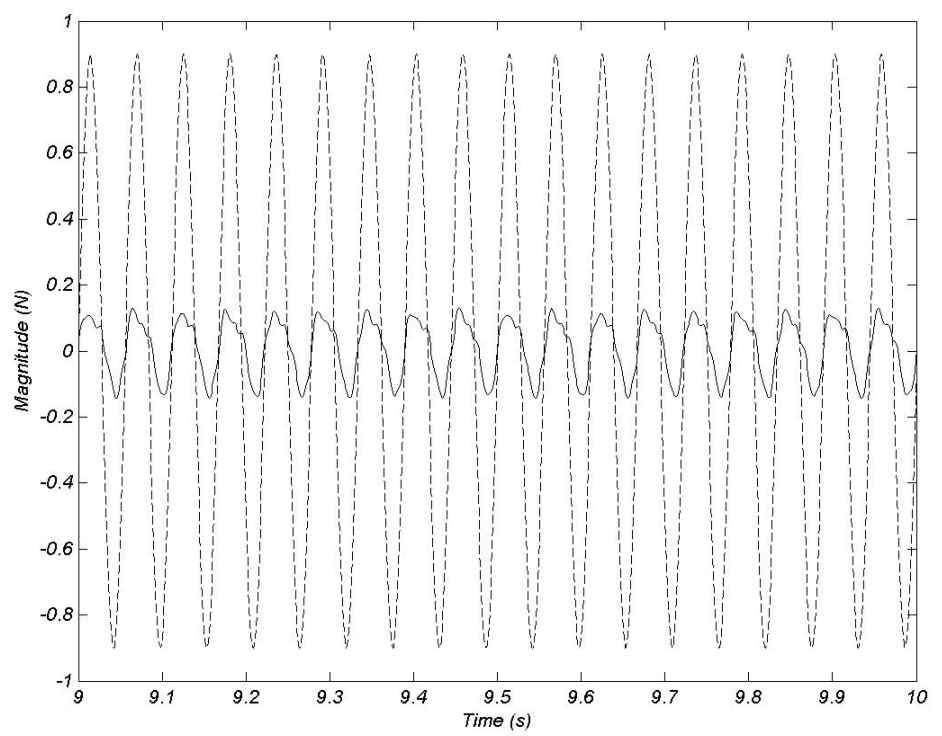

Fig. 28. Transmitted force variations of the system using the PD controller subjected to periodic engine disturbance at idling frequency at the final 1 seconds of the simulation. Open loop (-) and NN controlled (solid).

It can be observed from Figs 29 and 30 the magnitude of the steady state response of the neural network controlled system is much lower by approximately $60 \%$. Thus, the NARMA-L2 neural controller shows a better performance than the PD and PID tuned using the Ziegler-Nichols tuning rule.

\section{Conclusion}

Engine mounting system is an essential element to prevent engine from transmitting its vibration to the chassis and thus to improve the comfort of the passenger. The contradicting performance of the passive engine mounting system has led to the evolution of active engine mounting system which are able to reduce engine vibration effectively even at frequencies below the natural frequency. One of the best candidates for actively isolating the vibration is the neural network controller. The paper has presented the performance of the neural network controller specifically the NARMA-L2 controller compared to PD and PID controllers tuned using the Ziegle-Nichols tuning method. From the result obtained it can be concluded that the neural network has shown better performances in rejecting impulse and sinusoidal disturbances from the engine and thus isolating the transmitted force from the chassis even though the overshoot of the controller is high. It was shown by other researches such as in [38] that the NARMA-L2 has the behavior of producing large overshoot and a phase shift when implemented as a controller. Therefore, the researcher in [37] has introduced appropriate design strategies to reduce the high overshoot and to smooth out the control action of the controller. Even though the NARMA-L2 controller showed a degrading behavior in terms of its overshoot and phase error it has shown other superior capabilities such as good disturbance rejection which is the main criteria for this research and it is not the authors' intention to overcome the high overshoot that is produced by the controller. 


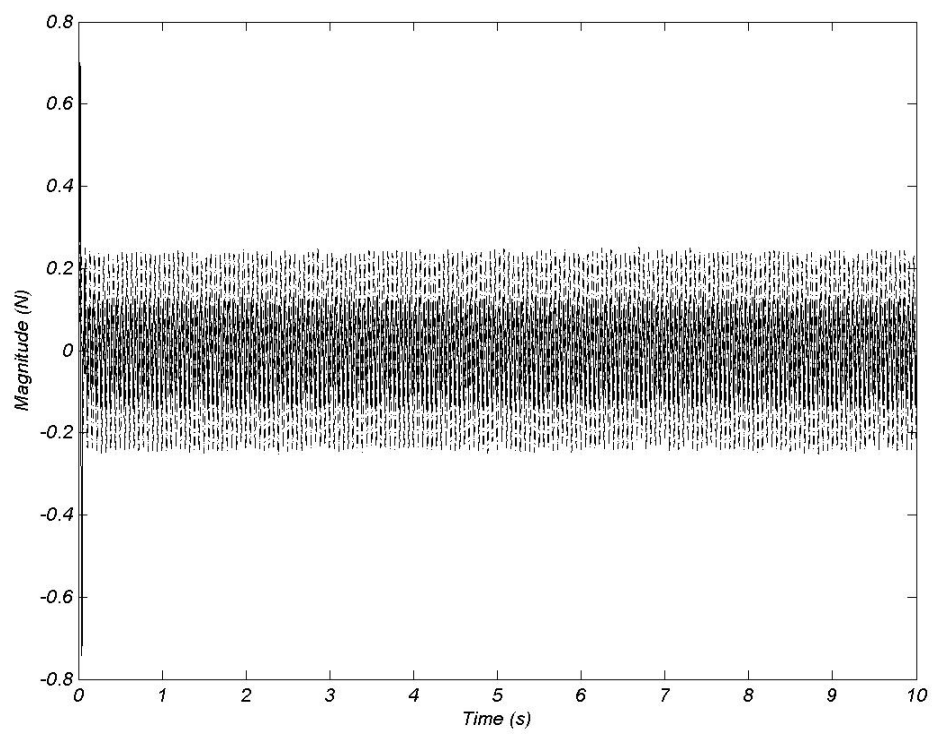

Fig. 29. Transmitted force variations of the system using the both PID and NN controllers subjected to periodic engine disturbance at idling frequency. PID controlled (-) and NN controlled (solid).

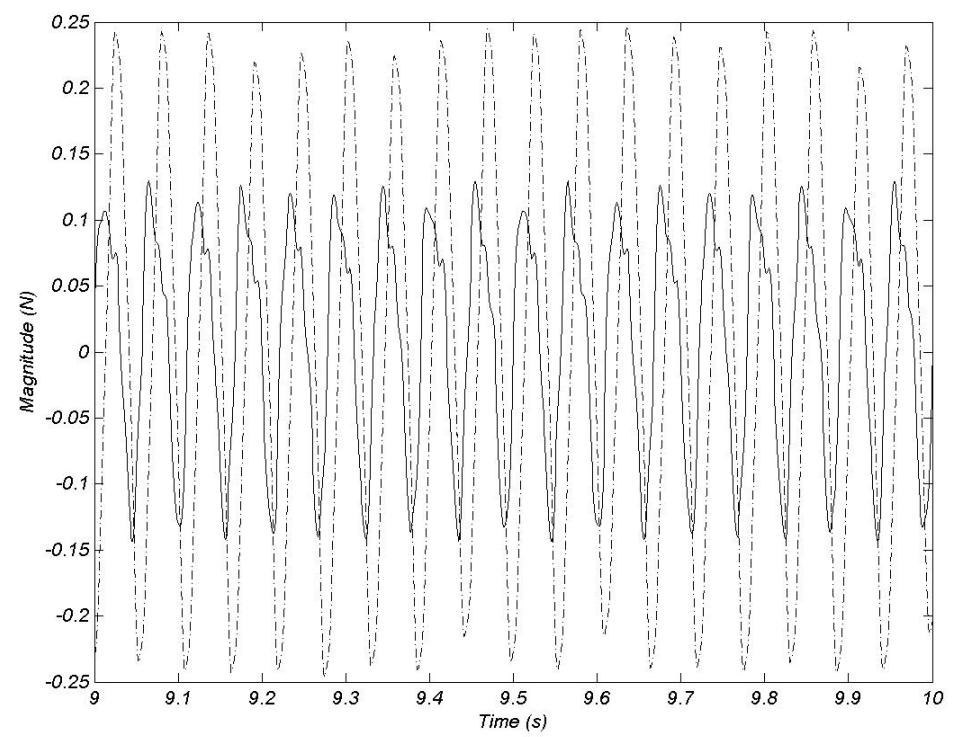

Fig. 30. Transmitted force variations of the system using the both PID and NN controllers subjected to periodic engine disturbance at idling frequency at the final 1 seconds of the simulation. PID controlled (-) and NN controlled (solid).

The advantage of NN control to PD or PID is that no mathematical model of the plant is necessary to design the controller and thus reducing mathematical error modeling. The model considered is only an engine suspended by two engine mountings on the front and on the rear and only subjected to force disturbance. For future work the model can be extended to two degree of freedom system where the engine is also subjected to rotational disturbance. Furthermore, the robustness of the neural network controller should be investigated for stability purposes. 


\section{References}

[1] Y. Yu, N.G. Naganathan and R.V. Dukipati, A literature review of automotive vehicle engine mounting systems, Mechanism and Machine Theory 36 (2001).

[2] C. Olsson, Active automotive engine vibration isolation using feedback control, Journal of Sound and Vibration 294 (2006).

[3] D.A. Swanaon, Active Mounts for Vehicles, SAE Paper \# 932432.

[4] A.J. Hillis, A.J.L. Harrison and D.P. Stoten, A comparison of two adaptive algorithms for the control of active engine mounts, Journal of Sound and Vibration 286 (2005).

[5] C. Bohn, A. Cortabarria, V. Härtel and K. Kowalczyk, Active control of engine-induced vibrations in automotive vehicles using disturbance observer gain scheduling, Control Engineering Practise 12(8) (2004).

[6] R. Singh, Dynamic design of automotive systems: Engine mounts and structural joins, Sădhanā 25(3) (2000).

[7] R. Shoureshi and T. Knurek, Automotive Applications of a Hybrid Active Noise and Vibration Control, IEEE Control Systems Magazine 6(6) (1996).

[8] J. Yang, Y. Seumatsu and Z. Kang, Two-Degree-of-Freedom Controller to Reduce the Vibration of Vehicle Engine-Body System, IEEE Transactions of Control System Technology 9(2) (2001).

[9] C.-W. Lee, Y.-W. Lee and B.-R. Ching, Performance test of active engine mount system in passenger car, Seventh International Congress on Sound and Vibrations, Germany, July 2000.

[10] M. Müller, H.-G. Eckel, M. Leibach and W. Bors, Reduction of noise and vibration in vehicles by an appropriate engine mount system and active absorbers, SAE Technical Paper \#960185.

[11] H.R. Karimi and B. Lohmann, Haar wavelet-based robust optimal control for vibration reduction of vehicle engine-body system, Electrical Engineering 89 (2007).

[12] T. Ushijima and S. Kumakawa, Active engine mount with piezo-actuator for vibration control, SAE Technical Paper \#930201.

[13] A.M. Beard, D.W. Schubert and A.H. von Flotow, A pratical product implementation of active/passive vibration isolation system, Active Control of Vibration and Noise 75, ASME, 1994.

[14] J.A. Snyman, P.S. Hyens and P.J. Vermeulen, Vibration Isolation of mounted engine through optimization, Mechanical Machine Theory 30(1) (1994).

[15] Z.-D. Ma and N.C. Perkins, An efficient multibody dynamics model for internal combustion engine system, Multibody System Dynamics 10 (2003).

[16] M. Müller, U. Weltin, D. Law, M.M. Roberts and T.W. Siebler, The effect of engine-mounts on noise and vibration behavior of vehicles, SAE Technical Paper \#940607.

[17] Y. Hagino, Y. Furuishi, Y. Makigawa, N. Kumagai and M. Yoshikawa, Active control for body vibration of FWD car, SAE Technical Paper \#860552.

[18] W.-H. Zhu, B. Tryggvason and J.-C. Piedboeuf, On active acceleration control of vibration isolation systems, Control Engineering Practice 14(8) (2006).

[19] K.S. Narendra, Neural networks for control: Theory and practice, Invited Paper, Proceedings of the IEEE 84(10) (October 1996).

[20] K.S. Narendra and S. Mukhopadhyay, Adaptive control using neural networks and approximate models, IEEE Transactions on Neural Networks 8(3) (1997).

[21] S. Mukhopadhyay and K.S. Narendra, Disturbance rejection in nonlinear systems using neural network, IEEE Transactions on Neural Networks 4(1) (1993).

[22] S.D. Snyder and N. Tanaka, Active control of vibration using neural network, IEEE Transactions on Neural Networks 6(4) (1995).

[23] C.L. Zhang, D.Q. Mei and Z.C. Chen, Active vibration isolation of a micro-manufacturing platform based on a neural network, Journal of Materials Processing Technology 129 (2002).

[24] A.G. Zadeh, A. Fahim and M. El-Gindy, Neural network and fuzzy logic applications to the vehicle systems: literature survey, International Journal of Vehicle Design 18(2) (1997).

[25] R. Hampo and K. Marko, Neural network architectures for active suspension control, Proceedings of the International Conference on Neural Networks, Seattle, 1991.

[26] S. Yildirim, Vibration control of suspension systems using a proposed neural natwrok, Journal of Sound and Vibration 277 (2004).

[27] J. Wagner and X. Liu, Nonlinear Modeling and Control of Automotive Vibration Isolation Systems, Proceedings of the American Control Conference, 2000.

[28] A.G. Zadeh, A. Fahim and M. El-Gindy, Neural Network and Fuzzy Logic Applications to Vehicle Systems: Literature Survey, International Journal of Vehicle Design 18(2) (1997).

[29] S.N. Sivandam, S. Sumathi and S.N. Deepa, Introduction to neural networks using Matlab 6.0, Tata McGraw-Hill, New Delhi, 2006.

[30] J.D. Fadly, W.F. Faris and M. Wahyudi, International of Journal of Vehicle Noise and Vibration, in Press.

[31] D.A. Swanson, Active Engine Mounts for Vehciles, SAE Technical Paper \#932432.

[32] T. Ushijima, K, Takano and H. Kojima, High performance hydraulic mount for improving vehicle noise and vibration, SAE Technical Paper \#880073.

[33] L.R. Miller and M. Ahmadian, Active mounts - a discussion of future technological trends, Inter-noise Conference, Toronto, Canada, July 1992.

[34] C.R. Fuller, S.J. Elliot and P.A. Nelson, Active Control of Vibration, Academic Press Limited, London, 1996, 72-76.

[35] G.F. Franklin, J.D. Powel and A. Emami-Naeni, Feedback Control of Dynamic Systems, 4th Edition, Prentice Hall, New Jersey, $221-224$.

[36] R.C. Hibbeler, Engineering Mechanics-Dynamics, Third Edition, SI Edition, Precntice Hall Singapore, 2004.

[37] H. Demuth and M. Beale, Neural Network Toolbox for Use with Matlab, Mathworks, 1992.

[38] A. Pukrittayakamee, O. De Jesus and M.T. Hagan, Smoothing the control action for NARMA-L2 controllers, IEEE Transactions 3(2002). 

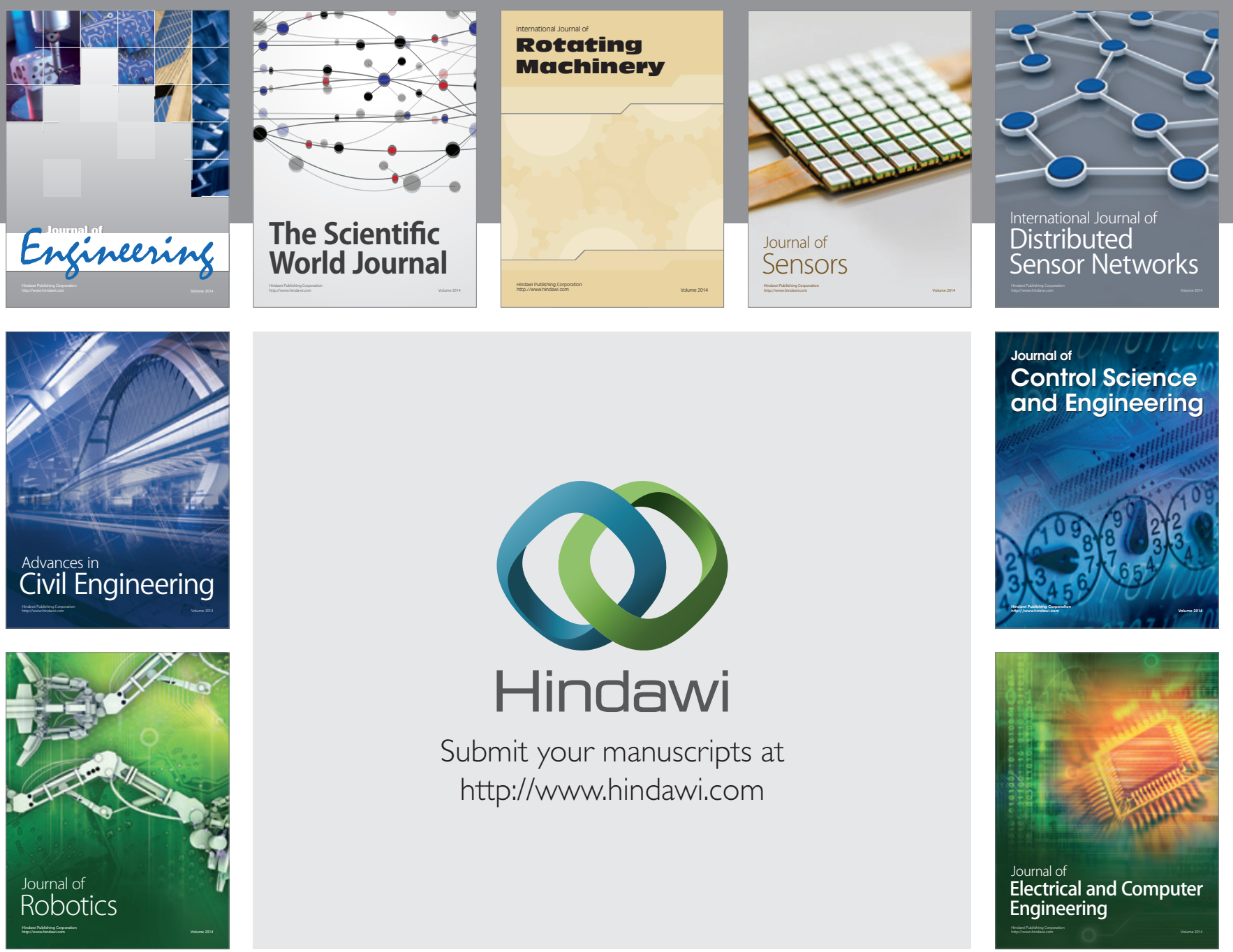

Submit your manuscripts at

http://www.hindawi.com
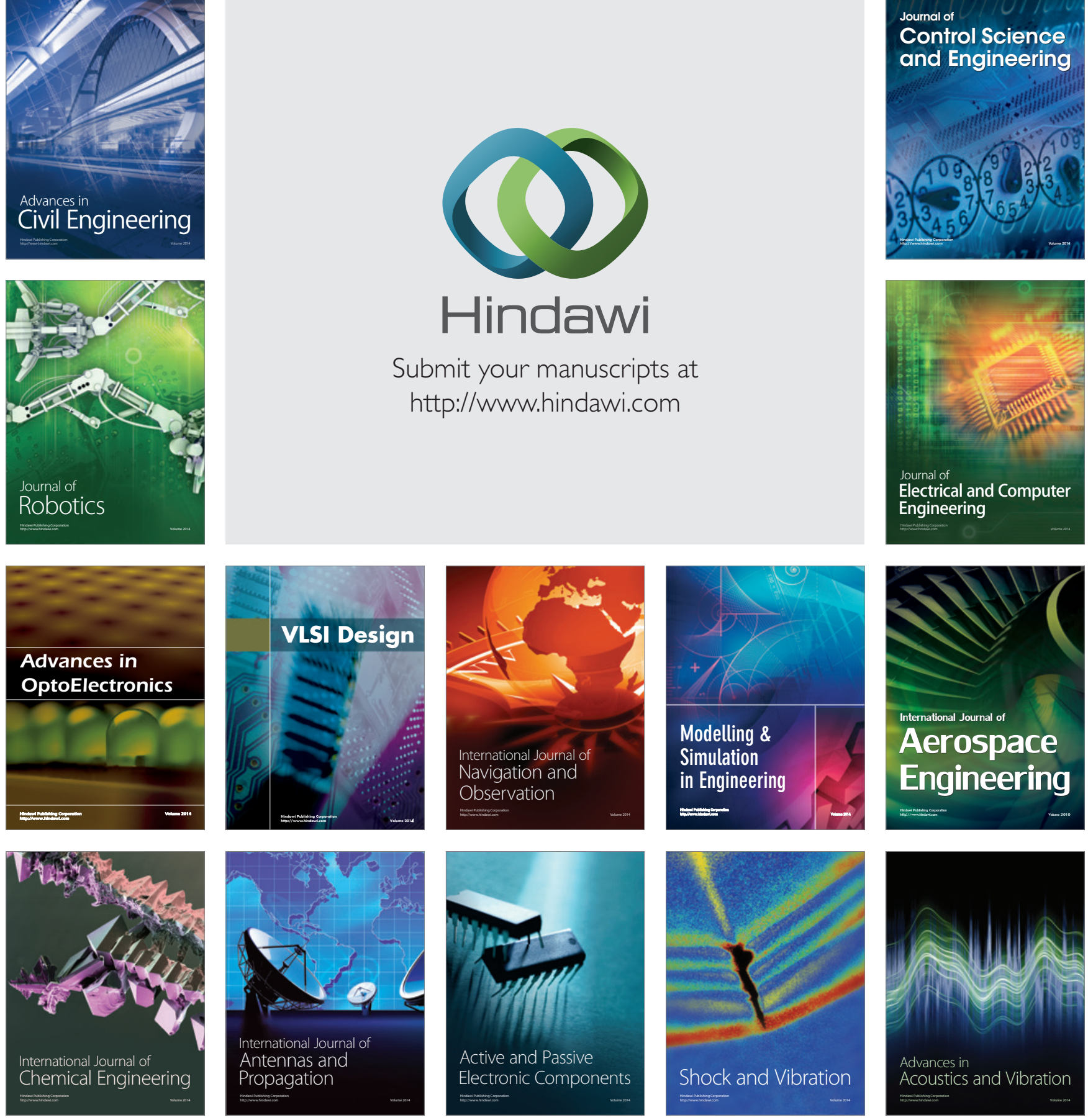